\title{
UNIDADES DE MEDIDAS: UM ESTUDO DOS SABERES MILENARES DOS AGRICULTORES DA ZONA RURAL DE SÃO RAIMUNDO NONATO
}

Units of measures: a study of millennial knowledge of farmers of the rural area of São Raimundo Nonato (PI - Brazil)

\author{
GESIVALDO DOS SANTOS SILVA ${ }^{1}$ \\ JORDÂNIA CAFÉ DOS SANTOS ${ }^{2}$
}

RESUMO: O presente trabalho tem como objetivo mostrar um estudo investigativo das unidades de medidas não formais dos trabalhadores da zona rural de São Raimundo Nonato(Piauí). Para o desenvolvimento da parte teórica buscamos trabalhos sobre a região sul do Piauí, em particular São Raimundo Nonato, a sua localização, a economia e os aspectos gerais. Nesta busca investigamos a vida dos moradores da zona rural, onde buscamos estudar as unidades de medidas não formais que estes usam ou usavam em suas atividades de medidas de terras. Postergada essa busca, elaboramos uma atividade com essas unidades de medidas e levamos aos alunos do $3^{\circ}$ ano do IFPI/ São Raimundo Nonato curso de Informática, em seguida organizamos as respostas dos alunos em categorias, onde destacamos no escopo do artigo.

Palavra-chave: São Raimundo Nonato. Trabalhadores Rurais. Unidades de Medidas.

ABSTRACT: The present work aims to show an investigative study of the units of non-formal measures of workers in the rural area of São Raimundo Nonato (Piau1). For the development of the theoretical part we look for works on the southern region of Piauí, in particular São Raimundo Nonato, its location, the economy and the general aspects. In this research we investigate the life of rural dwellers, in order to study the units of non-formal measures that they use or used in their activities of land measures. After this, we elaborated an activity with these units of measures and took to the students of the 3rd year of the IFPI / São Raimundo Nonato course of Informatics, then we organized the answers of the students in categories, where we emphasize in the scope of the article.

Key words: São Raimundo Nonato. Rural Dwellers. Units of measurement.

\footnotetext{
${ }^{1}$ Mestre em Ensino de Ciências Naturais e Matemática. Professor do IFMA.

2 Graduanda em Matemática no IFPI.
} 


\section{INTRODUÇÃO}

São Raimundo Nonato tem suas raízes fortalecidas no catolicismo, fruto das expedições dos Padres Mercedários, cujo nome é dado em homenagem ao Santo português Padroeiro da cidade. Este nome é dado pelo decreto regional 8.832, o qual criou assim a Freguesia Eclesiástica de São Raimundo Nonato. Esta freguesia estava antes dividida em maior parte no município de Jaicós e em menor parte no município de Jerumenha que, devido à distância e à falta de comunicação entre eles, não tinham como fazer prevalecer seus alegados domínios nem manter a hegemonia territorial pretendida. A Freguesia de São Raimundo Nonato tinha sua sede no lugar chamado Confusões que se localizava no extremo poente de seu território. Permaneceu neste local por cerca de quatro anos, até que, por efeito da Lei provincial número 35, de 27 de agosto de 1836, transferiu-se para a Fazenda Jenipapo cuja população dedicava-se à lavoura e à pecuária. Segundo Oliveira (2013), em 1850 a Lei provincial número 257 de 12 de agosto elevou a freguesia à categoria de vila, mantendo a mesma denominação e sede. No entanto, sua instalação deu-se apenas em 04 de março de 1851 quando Inácio Francisco da Mota era governador da província. O referente distrito judiciário ficou subordinado à Oeiras (Primeira Capital do estado) até 1859 e posteriormente à Jaicós, quando foi elevada à categoria de Comarca, por efeito da Lei Provincial número 468, de 12 de agosto do mesmo ano.

Seu território permaneceu inalterado até o ano de 1872, quando foi instalada a Vila de São João do Piauí, ficando desmembrada toda zona que compreende os municípios de São João do Piauí, Canto do Buriti, Socorro do Piauí, Paes Landim, Lagoa do Barro do Piauí, Brejo do Piauí, Campo Alegre do Fidalgo, Capitão Gervásio de Oliveira, João Costa, Nova Santa Rita, Pajeú do Piauí, Pedro Laurentino, Ribeira do Piauí e Tamboril do Piauí.

Mas nem sempre foi assim. No painel do centenário produzido pela UNIVASF (2012), encontramos uma citação importante que destacaremos:

São Raimundo Nonato é uma vila de casas térreas, construídas com adobes, pavimentadas de tijolos, caiadas, cobertas de telhas, sem forros. Há duas ruas extensas, estreitas, sem calçamento, duas praças, e casas esparsas sem ordem. População de 2.000 almas mais ou menos. Uma igreja de arquitetura banal, pequeno mercado muito pobre, algumas casas comerciais com pouco sortimento e caríssimo. Duas escolas públicas, mal frequentadas. É cabeça de comarca. A municipalidade rende 10 contos por ano. A água é detestável, salobra, extraída de poços do riacho cortado depois do inverno, e de cacimbas nas secas. Não havia esgotos, nem se usam fossas para fezes. (BELISÁRIO PENA E ARTUR NEIVA, 1912, p.40).

Nesta citação o autor aponta muitos problemas enfrentados, entre eles a água, a educação e saneamento básico. Tudo era muito rudimentar, as famílias eram na grande maioria ruraneiras e a cidade não conseguia se desenvolver. 
Em 1912, São Raimundo Nonato foi emancipada, passando à categoria de cidade por ordem da Lei 669, em 25 de junho de 1912; porém, sua população vivia em grande parte na zona rural o que dificultou por muitos anos o avanço da cidade. Essa ligação com o campo foi uma característica marcante da população de São Raimundo Nonato.

A cidade que está localizada no sudoeste do estado do Piauí, a uma distância de aproximadamente 550 quilômetros da capital Teresina, é destaque nacional por abrigar a maior reserva arqueológica da América Latina, o Parque Nacional serra da Capivara, que privilegia a região berço do homem pré-histórico e do homem americano.

Após sucessivos cortes ocorridos dos desmembramentos de municípios vizinhos, o município de São Raimundo Nonato passou a ter os seguintes limites: ao norte Canto do Buriti e João Costa; ao Sul Fartura do Piauí e Dirceu Arcoverde; a Leste Coronel José Dias e São Lourenço e a Oeste Várzea Branca, Bonfim do Piauí e São Braz do Piauí.

São Raimundo Nonato por ser uma cidade polo tornou-se o maior centro de desenvolvimento da microrregião, compreendida por 16 municípios. Com uma população superior a 109 mil habitantes, são: Anísio de Abreu, Bonfim do Piauí, Brejo do Piauí, Canto do Buriti, Caracol, Coronel José Dias, Dirceu Arcoverde, Dom Inocêncio, Fartura do Piaú, Guaribas, Jurema, Pajeú do Piauí, São Braz do Piauí, São Lourenço do Piauí, Tamboril do Piauí, Várzea Branca. O que fortalece uma atividade comercial intensa na cidade de São Raimundo Nonato.

O Município de São Raimundo Nonato está localizado na mesorregião do Sudoeste piauiense e possui aproximadamente 31.744 habitantes e 2.606,8 $\mathrm{Km}^{2}$ (dados do IBGE,2010). É uma cidade que foi construída em um vale, localizando-se a aproximadamente $30 \mathrm{~km}$ do Parque Nacional Serra da Capivara.

$\mathrm{Na}$ região central da cidade, encontra-se a beleza dos casarões estilo colonial datados do século XIX e início do século XX, todos em bom estado de conservação, além de abrigar um museu que guarda as marcas das pegadas pré-históricas, cativada e desenvolvida por estudantes e pesquisadores na região, onde iniciou-se por Niéde Guidom, professora e pesquisadora responsável pela administração do parque e museu.

A cidade de São Raimundo Nonato tem suas origens nas grandes fazendas que se instalaram por aqui no início da colonização. O mapa 1 destaca a abrangência e localização da cidade. 
Figura 1: Cidade de São Raimundo Nonato, em relação ao estado do Piauí

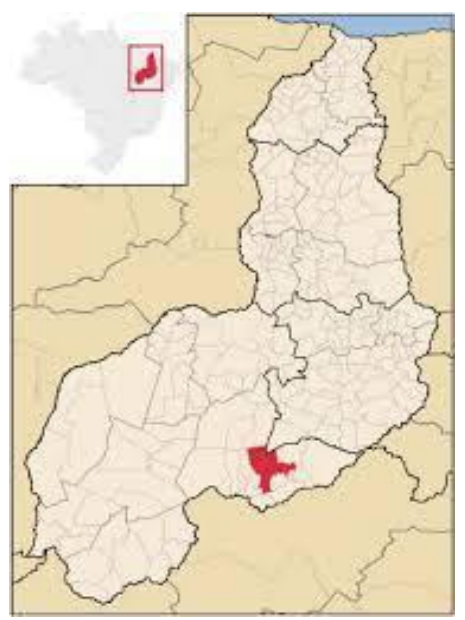

Fonte: <https://www.google.com.br/search?q=s\%C3\%A3o+raimundo+nonato $>$ Acesso em: 23/02/2016

O ponto que projetou o município de SRN para o Brasil e o mundo foi o Parque Nacional Serra da Capivara. São Raimundo Nonato, apesar de estar localizada nas caatingas do sudeste brasileiro região conhecida como Sertão Bruto, tem privilegiado pesquisas de referência no campo da Arqueologia liderada pela pesquisadora Niède Guidon.

\section{UNIDADE DE MEDIDAS: uma breve apresentação}

Em nossa civilização atual, os processos de medição são bastante complexos, a fim de satisfazerem às necessidades da ciência e da tecnologia. Em épocas remotas, o homem utilizou processos simples, suficientes para a sua técnica primitiva. Mas, quando começou a medir? Começou provavelmente quando ainda nem falava, pois poderia medir ou comparar um peixe com outro, a saber, qual o maior ou o menor. Também seria do seu conhecimento que certa quantidade de alimento saciaria sua fome. Obviamente, eram maneiras intuitivas de medir.

A partir do momento em que o homem passou a viver em grupos e à proporção que esses aglomerados cresciam, a necessidade de medir aumentava ainda mais. As maneiras como mediam as grandezas eram bastante simples: usavam partes do próprio corpo, como o comprimento do pé, a largura da mão ou a grossura do dedo, o palmo e a passada. 
Figura 2: Medidas dos pés

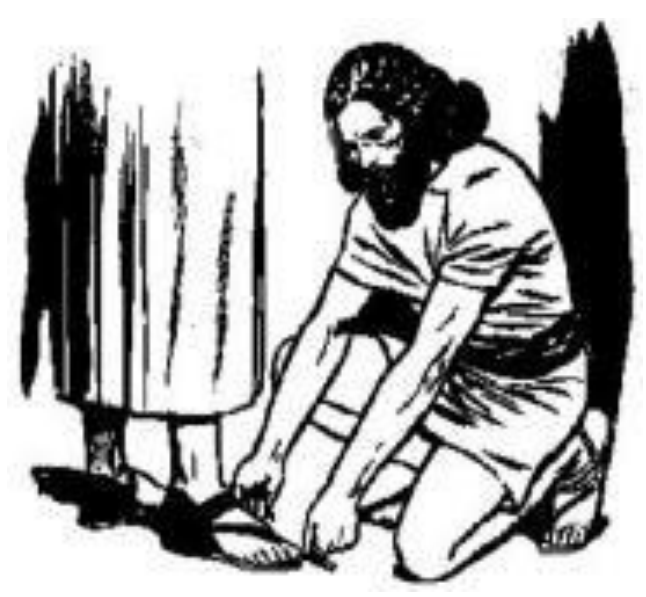

Fonte: Disponível em <http://www.fisica.net/unidades/pesos-e-medidas-historico.pdf $>$ Acesso em 20/02/2016.

Utilizavam ainda uma vara ou um bastão. Como usualmente se considera como a matemática mais antiga aquela resultante dos primeiros esforços do homem para sistematizar os conceitos de grandeza, forma e número; é por aí que começaremos focalizando de início o surgimento no homem primitivo do conceito de número e do processo de contar.

Eves (2004, p. 25) destaca que "o conceito de número e o processo de contar desenvolveram-se tão antes dos primeiros registros históricos (há evidências arqueológicas de que o homem, já há uns 50.000 anos, era capaz de contar, comparar) que a maneira como ocorreram é largamente conjectural". Não é difícil, porém, imaginar como isso provavelmente se deu. É razoável admitir que a espécie humana, mesmo nas épocas mais primitivas, tinha algum senso numérico, pelo menos ao ponto de reconhecer mais e menos quando se acrescentavam ou retiravam alguns objetos de uma coleção pequena, pois há estudos que mostram que alguns animais são dotados desse senso.

Com a evolução gradual da sociedade, tornou-se necessário registrar, contar objetos.

Uma tribo tinha que saber quantos eram seus membros e quantos eram seus inimigos e tornava-se necessário a um homem saber se seu rebanho de carneiros estava diminuindo. É provável que a maneira mais antiga de contar se baseasse em algum método de registro simples, empregando o princípio da correspondência biunívoca. Para uma contagem de carneiros, por exemplo, podia-se dobrar um dedo para cada animal. Podia-se também contar fazendo se ranhuras no barro ou numa pedra, produzindo-se entalhes num pedaço de madeira ou fazendo-se nós numa corda. Então, talvez mais tarde, desenvolveuse um arranjo de sons vocais para registrar verbalmente o número de objetos de um grupo pequeno. E mais tarde ainda, com o aprimoramento da escrita, foram surgindo arranjos de símbolos para representar esses números. Esse desenvolvimento hipotético encontra respaldo em relatórios de antropólogos que estudaram povos primitivos em nossa época. (EVES, 2004, p.26). 
Há evidências de que 2, 3 e 4 serviram como bases primitivas. Por exemplo, há nativos de Queensland que contam "um, dois, dois e um, dois e dois, muito", e alguns pigmeus africanos que contam " $a$, oa, ua, oa-oa, oa-oa-a e oa-oa-oa" para 1 , 2, 3, 4, 5 e 6. Uma certa tribo da Terra do Fogo compõe seus primeiros e poucos nomes de números na base 3 e algumas da América do Sul usam de maneira análoga o 4 (EVES, 2004, p. 26).

Algumas tribos que Eves destaca usaram ao longo de muitos anos a nasalidade para representar suas contagens, o que faz-nos supor desta leitura que o homem primitivo iniciou seus registros por meio de letras, que caracterizavam os números. Outro ponto importante que cabe mencionar aqui é que os primitivos contavam com bases pequenas, 1, 2,3,4 e até o cinco.

Como seria de esperar, o sistema Quinário ou sistema de numeração de base 5 , segundo Ifrah (2009), foi o primeiro a ser usado extensivamente. É especulado que este sistema tenha sido o primeiro pelo fato de uma mão ser um dispositivo prático para a contagem e o fato de ter cinco dedos.

Até hoje algumas tribos da América do Sul contam com as mãos: “um, dois, três, quatro, mão, mão e um" e assim por diante. Os Yukaghirs da Sibéria usam uma escala mista para contar "um, dois, três, três e um, cinco, dois três, um mais, dois três e dois, dez faltando um, dez". Ainda no início do século XIX se encontravam calendários de camponeses germânicos baseados no sistema quinário. (EVES, 2004, p.26).

Com o crescimento populacional das civilizações antigas, o homem criou necessidades de contar em tamanhos maiores, com esse crescimento civilizações foram erguidas, entre elas podese destacar os Maias, Egípcios e Babilônico, todos esses povos desenvolveram uma forma de contar seus objetos e fazer seus registros.

No entanto não foi suficiente, pois o homem precisou pesar, ou melhor, comparar massas. Nos primeiros tempos, o homem comparava a massa de dois corpos equilibrando-os um em cada mão (figura 2). Até que surgiu a primeira máquina de comparação: uma vara suspensa no meio por uma corda. 
Figura 4: Comparação de Massas

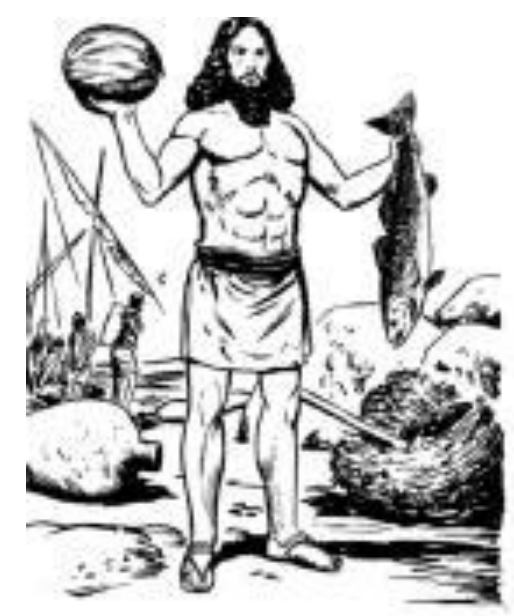

Fonte: Disponível em <http://www.fisica.net/unidades/pesos-e-medidas-historico.pdf> Acesso em 20/02/2016

Os objetos eram pendurados nas suas extremidades e se houvesse o equilíbrio, ou seja, se a vara ficasse na horizontal fixa eles possuíam a mesma massa. Os povos antigos padronizaram centenas de diferentes pesos e medidas para atender às necessidades de suas civilizações.

Com relação ao tempo, apesar de não poder segurá-lo ou guardá-lo, o homem conseguia medi-lo registrando as repetições dos fenômenos naturais periódicos. Qualquer evento familiar servia para marcar o tempo: o período entre um e outro nascer do Sol, a sucessão das luas cheias ou a das primaveras fizeram com que os antigos criassem seus calendários periódicos, o que auxiliava nos períodos de plantação e colheita dos cereais.

Você deve saber que assim como os antigos, os índios contavam os anos por invernos ou verões, os meses por luas e os dias por sóis. Tais cálculos não eram muito exatos, as horas de claridade entre o nascer e o pôr do sol variam muito durante o ano. Já o período que vai de uma lua cheia a outra permanecia constante. Logo os homens perceberam tal fato e concluíram que a maneira mais exata de medir o tempo era baseando-se na periodicidade de eventos em corpos celestes. O que lhe auxiliavam nos cultivos das lavouras, pois esta periodicidade era a forma como eles sabiam que estava adequada ao arado, pois sabiam que breve a terra seria molhada (chuva) e estava pronta para plantar ou colher.

O que nos chama atenção é que esse conhecimento chegou aos nossos dias, os sábios que vivem na zona rural, os agricultores, utilizam ainda essa periodicidade para realizar suas atividades de plantação e colheita, pois são os movimentos periódicos da lua que dizem quando é hora de plantar. Outro saber que é preservado até nossos dias é em relação às chuvas. Os sertanejos piauienses usam instrumentos naturais para descobrir se naquele ano haverá pouca ou muita chuva. A forma de medir é a seguinte: eles observam as árvores que existem nas margens dos lagos ou rios, se um pássaro fizer ninho nos galhos baixos, é porque naquele ano a chuva será 
pouca, o que não será suficiente para encher o lago ou rio, a um ponto de expulsá-lo. Se o ninho for feito nos galhos altos, significa que naquele ano haverá um bom inverno e que o lago será cheio. Esses saberes, advindos das culturas antigas, ainda hoje fazem parte do nosso meio.

Muitas outras invenções ou improvisos foram criados, principalmente na hora de cubar ${ }^{1}$ as terras. O sistema utilizado pelos agricultores para determinar comprimentos e medidas de áreas nas terras a serem preparadas e plantadas tem como base de medida a braça. Esta medida é equivalente a 2,20m no sistema métrico decimal. Eles utilizam cordas ou uma vara de madeira, sem marcações específicas para determinar o comprimento de cada braça. Ao atingir essa medida na região a ser preparada e/ou plantada eles marcam o local final do comprimento no chão com um pedaço de madeira ou medem novamente a partir deste ponto final delimitado, de forma que ao terminar a medida de uma braça já começam em seguida outra braça.

Ao entrevistar, o Senhor José Ribeiro dos Santos ${ }^{1}$, tesoureiro do Sindicato Rural de São Raimundo Nonato, e trabalhador rural, identificamos o uso da braça na zona rural de São Raimundo Nonato.

[...] A braça era medida, a gente se tira ela baseada em dois metros e vinte [...] No braço, você arriba o braço, levanta o braço quando você vê aqui é só dobrar o dedo e dava a braça. Entrevistadora: Assim sempre dava dois e vinte? Não, aí quem fosse mais alto a braça era maior, aquela menor saia menor, ou então, o cara tinha que completar com um palmo uma chave que seja (JOSÉ RIBEIRO DOS SANTOS, 2016).

Como se viu, a braça foi o primeiro instrumento de extensão usado como instrumento de medidas de comprimento e ainda hoje é usado nas comunidades rurais, pelos lavradores. Podemos ver na figura 5 , como era feita essa medida da braça.

\footnotetext{
1 Entrevista concedida por José Ribeiro dos Santos, Entrevista concedida na sede no sindicato rural do município de São Raimundo Nonato. [jan. 2016]. Entrevistadores: Gesivaldo dos Santos Silva e Jordânia dos Santos Café. São Raimundo Nonato (PI), 2016. 1 arquivo .mp3 (60 min.).
} 
Figura 5: Medindo a Braça

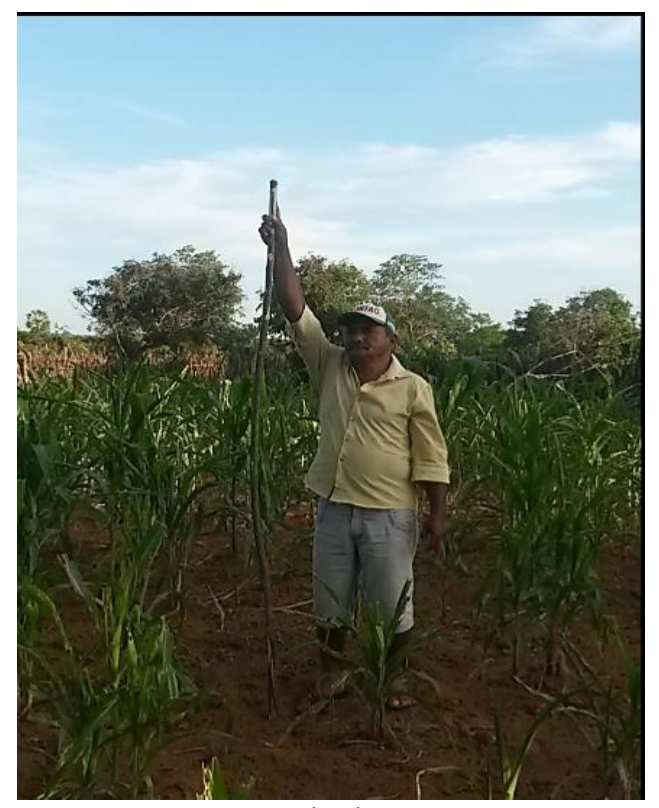

Fonte: Pesquisadora

As áreas que são medidas pelos agricultores servem para que as demarcações de terras sejam destinadas ao plantio de cereais, como o milho, feijão e a mandioca, comuns de serem plantados nessa região.

As contratações de trabalhadores para o preparo das terras eram feitas através de demarcações e, por meio dessas, efetuam o pagamento dos mesmos baseando-se em quantas contas e/ou tarefas, o mesmo preparou. A conta equivale a dez braças quadradas, ou seja, é uma área de um quadrado que tem a medida do lado igual a $22 \mathrm{~m}$ perfazendo uma área total de $484 \mathrm{~m}^{2}$.

A área da tarefa é igual a seis contas mais um quarto de uma conta, que tem ao todo 625 cubos. Outra relação interessante é que cada conta é equivalente a 100 cubos. "[...] A tarefa ela é um quadrado se mede vinte e cinco braças, aí faz aquele quadrado que dá cem braças o quadro, se torna uma tarefa" (JOSÉ RIBEIRO DOS SANTOS, 2016).

O acréscimo desse um quarto de conta deve-se ao fato de que se tivermos a área de uma tarefa, nesta caberiam seis contas ${ }^{2}$ inteiras. No entanto, faltariam 25 cubos para completar os 625 cubos que correspondem a uma tarefa. Logo, os 25 cubos são justamente um quarto de 100 (uma conta).

Dessa forma, a área total da tarefa corresponde a aproximadamente um valor que varia entre $3.000 \mathrm{~m}^{2}$ e $3.025 \mathrm{~m}^{2}$. Para obter a medida de grandes áreas, os agricultores utilizam a determinação um quadro, que é igual a vinte e cinco contas, uma área de aproximadamente $12.000 \mathrm{~m}^{2}$ ou $12.100 \mathrm{~m}^{2}$, visto que alguns agricultores trabalham com a medida de uma tarefa sendo igual a $3.000 \mathrm{~m}^{2}$. Nessas inter-relações também é possível relacionar a tarefa com o quadro. 
Podemos dizer que a área que correspondente a um quadro é a mesma área de quatro tarefas e uma conta, pois cada tarefa tem seis contas e um quarto de conta (25 cubos), ou seja, multiplicando as seis contas pelas quatro tarefas tem um total de 24 contas. Entretanto, falta uma conta para completar as 25 contas equivalentes a um quadro. Esta é justamente quatro vezes um quarto de conta (25 cubos), totalizando assim 100 cubos e tendo dessa forma uma conta. Há um conhecimento proporcional que subjazem essas práticas, com seus cálculos específicos, e que pretendemos investigar detalhadamente no próximo capítulo.

Outras formas de medidas usadas era o hectare: em escala oficial essa medida equivale a $10.000 \mathrm{~m}^{2}$. Para os agricultores ela teria um valor um pouco maior. "[...] A gente nunca se trabalhou com alqueiro se trabalha com hectare, o que quer dizer hectare? Hectare, um hectare ele se torna três tarefas e um quarto" (JOSÉ RIBEIRO DOS SANTOS, 2016).

Esses saberes são importantes para interligar saberes. Em outras regiões do país que se usa bastante o Alqueire, esta é uma medida de terra não oficial que equivale a 4 hectares de terra, em grandezas oficiais, equivale a 40.000 mil metros quadrado. Em linguagem apresentada, corresponde a 13 tarefas rurais.

De tempos em tempo, o sertanejo são-raimundense incorporava em algumas medidas as medidas oficiais, mas nunca abandonava as produzidas no campo. $\mathrm{O}$ carro tomou o lugar do lombo dos animais no transporte de mercadorias, as formas de tratar as distâncias que outrora era medida por meio de correntes, eram conhecidas como as léguas em vez de quilômetros. Ainda hoje é fácil ouvir e ver alguém tratando distâncias em léguas. Mas de fato o que é uma légua? A légua é uma medida de extensão que equivale a $6 \mathrm{~km}$.

A balança rústica que serve como um instrumento de medidas e pesos comparativos foi também bastante usada pelos agricultores do sul do Piauí como pode ser visto na figura 6 .

$\mathrm{Na}$ fala de José Ribeiro dos Santos, notamos um sentimento de saudade dos tempos em que a roça era escola, o alicerce principal da família. Os calos deixados em suas mãos grossas e o rosto queimado do sol refletem o quanto era cansativo o serviço braçal, porém era gratificante. Hoje esquecer esses instrumentos é deixar de lado os saberes que seu José Ribeiro dos Santos aprendeu a manusear e a manipular de acordo com suas necessidades. Ao passo que damos espaço aos novos conhecimentos científicos, sem validar esses saberes, estamos excluindo toda uma geração inteira que com inchada, foice e facão ajudaram a erguer uma cidade. 


\section{ANÁLISE DAS CATEGORIAS}

Da exposição que fizemos de todas as unidades de medidas estudadas e pesquisadas, procuramos identificar se os alunos do Instituto Federal de Educação, Ciência e Tecnologia do Piauí/ Campus São Raimundo Nonato, tinham conhecimento delas e como encarariam um problema envolvendo as unidades de medidas não convencionais. A nossa pesquisa de aplicação delimitou uma turma do ensino médio, onde fizemos um perfil do comportamento dos alunos frente aos desafios propostos. Desta atividade participaram 40 alunos.

A atividade foi composta de cinco perguntas e uma síntese de familiarização das unidades de medidas não convencionais, conforme mostraremos abaixo.

\section{Atividades}

Familiarizando-se com as unidades imediatas não convencionais, o aluno terá que ler o enunciado que apresentaremos para responder as perguntas feitas abaixo.

\section{Medidas agrárias}

Hectare: equivale a 3 tarefas e um quarto da tarefa. (10.000 metros quadrados) Tarefa: Equivale a uma área de 25 braças por 25, ou seja, o seu perímetro equivale a 100 braças. $\left(3.025 \mathrm{~m}^{2}\right)$

Braça: 2,20 metros.

Prato: Equivale a 2 litros, que cada litro equivale a 750 gramas.

Medida: Equivale a oito pratos.

Quarta: trinta e dois pratos.

Surrão: uma quarta.

Saca: 40 pratos $(60 \mathrm{~kg})$.

Uma carga: dois aiós.

Seis cargas: quatro sacos de farinha e um saco e meio de tapioca.

Atividade1: Expresse as unidades abaixo em nosso sistema métrico decimal:

\begin{tabular}{|l|l|}
\hline $\begin{array}{l}\text { Unidades Agrárias (Sistema de Medidas não } \\
\text { convencionais) }\end{array}$ & $\begin{array}{l}\text { Sistema de medidas convencionais } \\
\text { (metros, quilograma) }\end{array}$ \\
\hline 5 Hectares de Terra & Equivale a: \\
\hline 2 Tarefas & Equivale a: \\
\hline 7 braças em linha reta & Equivale a: \\
\hline 3 pratos de farinha & Equivale a: \\
\hline 4 quartas de milho & Equivale a: \\
\hline 2 Surrões de Arroz & Equivale a: \\
\hline 2 sacas de tapioca & Equivale a: \\
\hline
\end{tabular}


Atividade 2: Relacione as colunas por meio de setas, apresentando as que correspondem a unidades equivalentes.

\begin{tabular}{|lll|}
\hline \multicolumn{1}{|c|}{ Coluna 1 } & \multicolumn{1}{c|}{ Coluna 2 } \\
\hline & & \\
1) & $2.000 .000 \mathrm{~m}^{2}$ & 6) $12 \mathrm{pratos}$ \\
2) & $2 \mathrm{braças}$ & 7) $480 \mathrm{~kg}$ \\
3) & $720 \mathrm{~kg}$ & 8) $6050 \mathrm{~m}^{2}$ \\
4) & $8 \mathrm{sacas}$ & 9) $200 \mathrm{Hectares}$ \\
5) & $18 \mathrm{~kg}$ & 10) 15 Surrões \\
\hline
\end{tabular}

Atividade 3: Seu Francisco das Chagas limpa duas tarefas de terra por dia e gasta 1 dia para realizar o plantio de milho em cada tarefa. Esse trabalhador resolveu limpar 12 tarefas de terra para seu plantio, porém a meteorologia aponta que no $10^{\circ}$ dia cairá uma chuva, e sua plantação deve acontecer antes da chuva. Analisando o problema acima, pergunta-se: quantos homens seriam necessários para realizar a limpeza da terra e o plantio antes da chuva tendo o mesmo rendimento de seu Francisco?

Atividade 4: Após 3 meses, chega a época da colheita. Seu Francisco colheu 15 sacas de milho por tarefa plantada. Ele resolveu vender sua mercadoria no prato, só que o transporte da roça até a cidade é feito em jumentos sobre Aiós. Quantos surrões de milho ele colheu e quantas viagens ele teve que dar para transportar toda mercadoria com apenas um jumento, sendo que um jumento transporta 40 pratos em cada Aió?

Atividade 5: Seu João precisa colher 15 sacas de feijão em cada um dos seus 10 hectares e transportar para a feira com dois jumentos, cada um consegue transportar $60 \mathrm{~kg}$ em cada aió, porém seu João tem que plantar uma quarta para que essa colheita seja realizada. Seu João ainda precisa pagar trabalhadores para lhe ajudar. Sabendo que cada trabalhador cobra $\mathrm{R} \$ 1,30$ por quilo de feijão colhido, que seu João contratou apenas 2 trabalhadores e que o preço que é vendido/comprado na feira é R \$ 5, seu João terá lucro ou prejuízo? E de quanto?

\section{Analisando as Respostas}

Categoria 1: Análise da Aplicação Tarefa 1

Dentre as sete alternativas, apenas três alunos acertaram por completo, oito alunos erraram apenas uma, três alunos erraram duas e quatro alunos erraram três alternativas. Esses erros foram comuns entre os alunos e ocorreram devido a vários fatores: o primeiro erro ocorreu devido aos alunos não terem prestado atenção no significado/regra para a medida 
prato, pois o mesmo equivale dois litros ou 750 gramas resultando em 1,5kg, aproximadamente, e a resposta foi calculada como se a medida fosse 750 gramas o prato inteiro.

Um segundo erro foi no que se refere a transformar surrão em quilos, pois os mesmos esqueceram que na atividade eram dois surrões e a resposta que os alunos apresentaram foi baseada em apenas um.

O terceiro erro foi notado devido ao aluno não ter prestado atenção que a questão queria o valor de quatro quartas e a resposta apresentada pela grande maioria foi de apenas uma quarta, o que equivale a 48 quilos e não 192 quilos que é a resposta correta; por último, o aluno em vez de transformar o surrão em quilos, transformou em medida de prato, mas com nomenclatura de quilos.

Foram questionados sobre o conhecimento das unidades de medidas apresentadas e o que acharam da atividade. Entre os dezoito alunos que responderam a atividade, cinco alunos não conheciam essas unidades de medidas, responderam que acharam a atividade interessante e autoexplicativa e com a atividade passaram a conhecer essas unidades de medidas que são utilizadas na roça e que ajudam o raciocínio.

Treze alunos afirmaram que conheciam as unidades de medidas, falaram que já haviam trabalhado com os pais, citaram exemplos como hectare, saca e prato, mas que não sabiam converter essas medidas para o nosso sistema de medidas. Uma resposta chamou atenção, o aluno afirmava o seguinte: conhecia essas medidas, porque era da roça e seus familiares utilizam essas unidades de medidas até hoje, porém não sabia que tinha relação direta com as unidades de medida da escola. O que mostrou que essas unidades estão sendo repassadas a outras gerações, mesmo que em pouca escala.

Os alunos responderam que a atividade é muito interessante e proveitosa, visto que puderam conhecer novas medidas que são diferentes das que são vistas na sala de aula e nos livros didáticos e que é muito importante por que mostra o conhecimento matemático existente na zona rural.

\section{Categoria 2: Análise da aplicação Tarefa 2}

$\mathrm{Na}$ Tarefa 2, foram conferidos que 17 alunos acertaram toda a tarefa, porém não recolhemos as folhas de rascunhos para averiguação dos cálculos feitos, o que nos impossibilitou de fazer uma análise mais detalhada. No entanto, podemos afirmar que nessa atividade houve um envolvimento maior dos alunos, percebemos que eles estavam mais concentrados, percebemos também que eles usaram as folhas em branco para formar seus pares de contas e assim transcrever para a tarefa que estávamos propondo. Apenas um aluno não conseguiu resolver a 
tarefa por completo, visto que ele errou a conversão da unidade da saca e do prato para o sistema convencional, trocando os valores de um pelo do outro.

Categoria 3: Análise da aplicação Tarefa 3

Nesta tarefa era necessária a compreensão das unidades de medidas agrárias e transformá-las para as unidades de medidas convencionais e a conexão entre as informações estabelecidas.

Os alunos não interagiram com o mesmo entusiasmo nessa tarefa, não compreendemos o porquê, talvez tenha sido o nível de dificuldade, conforme expressões relatadas pelos alunos em sala. Nesta atividade, cinco alunos deixaram de fazer a atividade, os demais interagiram. Dos que fizeram, 5 alunos não deixaram o cálculo na tarefa, permitindo-nos apenas a resposta, afirmando que a quantidade de homens necessário estava entre 2 e 6 homens. Cinco alunos responderam que o mínimo eram 2 trabalhadores para a realização do trabalho.

Os que responderam que o mínimo eram 2 trabalhadores verificaram assim: dois alunos calcularam quantos dias eram necessários para um só homem realizar a tarefa, achando um valor de doze dias, sendo um equívoco. Pois o mesmo não ateve que para realizar o plantio o trabalhador gasta mais dias que para limpar. Em seguida, calculou os dias necessários para dois homens, com o mesmo equívoco anterior, encontrou 6 dias, mas conseguiu identificar que o mínimo era de dois trabalhadores. Já três alunos fizeram corretamente o cálculo ao verificar que um homem utiliza 18 dias para realizar a tarefa e que para realizá-la a tempo, antes da chuva, tem-se apenas 9 dias, o que resulta em dividir o número mínimo de um homem pelo número máximo de dias que se tem: que é 9; logo, resulta em dois, que é o número mínimo de homens necessários.

Três alunos responderam diferente, dois deles apenas deixaram o valor na atividade, sendo que um disse que precisava de 9 trabalhadores e o outro que eram necessários 5 homens. O terceiro aluno respondeu que eram necessários 6 homens incluindo o dono da roça. Esse aluno fez a divisão entre o número de tarefas de terra e a quantidade de atividades que era necessário realizar, ou seja, limpar e plantar, encontrando assim o valor seis.

\section{Categoria 4: Análise da Aplicação Tarefa 4}

Nessa tarefa, apenas 10 alunos responderam, entre eles dois acertaram. Eles fizeram o seguinte: multiplicaram a quantidade de sacas de uma tarefa pela quantidade de tarefas, encontrando assim 180 sacas. Em seguida, converteram para o surrão, encontrando 225 surrões. Para calcular a quantidade de viagens, primeiro calcularam quantos quilos o jumento podia carregar, fazendo a conversão de pratos para quilos, por último calcularam a quantidade de 
quilos colhidos e dividiram pela quantidade que o jumento suporta carregar, encontrando assim a quantidade de viagens necessárias para o transporte.

Dentre os alunos que não acertaram a questão, três não fizeram as conversões certas e confundiram algumas medidas, além de terem calculado para valores apenas de uma tarefa e não de 12 como pedia a questão. Um aluno até conseguiu entender e fazer algumas conversões, porém ao chegar na medida de prato que era para converter para surrões apenas dividindo pela quantidade de pratos que vale um surrão, e também dividir a quantidade de pratos encontrada pela quantidade de pratos que o jumento poderia carregar, encontrando assim, a quantidade de viagens. $\mathrm{O}$ aluno fez uma multiplicação por um número que nem está contido nas medidas agrárias. Outros 4 alunos fizeram os cálculos certos, porém não verificaram o fato que eram 12 tarefas a calcular, e eles fizeram os cálculos como se fosse apenas em uma tarefa de terra.

\section{Categoria 5: Análise da Aplicação Tarefa 5}

Catorze alunos deixaram de responder essa tarefa, sendo que apenas quatro responderam. E não houve nenhum acerto nessa questão. Porém os erros ocorreram por que os alunos em vez de calcularem o valor do quilo de feijão por cinco reais e pagar ao trabalhador 1,30 pelo o quilo, eles calcularam esses valores, mas com a saca, resultando em valor extremamente diferente do que o exercício pedia. Um segundo aluno calculou corretamente, apenas não verificou que era necessário calcular o valor gasto para plantar, ou seja, além de pagar o que comprou para plantar deveria ter calculado o valor para 2 trabalhadores e fez como se fosse apenas um trabalhador, resultando em lucro maior. Os outros dois participantes da pesquisa calcularam corretamente, apenas encontraram um valor diferente ao multiplicar o valor pago ao trabalhador, o restante da questão ficou errada devido a esse percurso não convencional.

\section{CONSIDERAÇÕES FINAIS}

Do exposto, pontuamos nossa amostra da aplicação do trabalho, resumindo de forma sucinta o que aconteceu em sala de aula na aplicação e o que fizeram durante esse percurso, entre leitura do problema, interpretação da situação e resolução. Nosso trabalho de cunho investigativo tinha a finalidade de provocar nos alunos conhecer as unidades de medidas utilizadas pelo o homem do campo em São Raimundo Nonato e assim preservá-las, pois a nosso ver foram criadas em um aspecto de necessidades por culturas passadas, anteriores à nossa e que hoje ainda existem em nosso meio e o nosso trabalho é a prova da sua existência. 


\section{REFERÊNCIAS}

CONRADO, A. L. Etnomatemáticas: sobre a pluralidade nas significações do programa etnomatemática. In: RIBEIRO, J. P. M.; DOMITE, M. C. S.; FERREIRA, R. [Orgs.]. Etnomatemática: papel, valor e significado. São Paulo: Zouk, 2004.

D’AMBRÓSIO, U. Etnomatemática: Elo entre as tradições e a modernidade.5. ed. Belo Horizonte: Autêntica, 2001.

EVES, H. Introdução a História da Matemática. Trad. 9 ed. São Paulo, Unicamp. 2004.

FEITOSA, A. A Etnomatemática e seus pressupostos históricos. Disponível em:< http://www.infoescola.com/matematica/a-etnomatematica-e-seus-pressupostos-historicos/> Acesso em jan.2016.

FREIRE, M.D. S; SILVA, M.G.L.D. Uma Proposta Didática Para Trabalhar a Estratégia de Resolução de Problemas na Formação de Professores de Química. In: ARAÚJO, M.F.F.D; MOHR.A; EDUFRN, 2012.

GONÇALVES, P. G. F. A Etnomatemática dos trabalhadores das cerâmicas de RussasCE e o contexto escolar: Delineando recomendações a partir de uma experiência Educacional. 2013. 122 f. Dissertação (Mestrado em Ensino de Ciências Naturais e Matemática) Universidade Federal do Rio Grande do Norte. Natal, 2013.

IFRAH, G. Números: A história de uma grande invenção. Trad. Stella M. de Freitas Senra. 11 ed. São Paulo: Globo. 2005.

LIMA, J.A.C; NASCIMENTO, S.D.M.Z; SANTOS, D.M.E. Abordagem Pedagógica para um Sistema de Medidas utilizado no Sertão Pernambucano: Litro, Cuia e Saca. Revista Gestão Universitária, v.2, n.1, p. 01 - 17, jul - dez. 2014.

LUCENA, I.C.R.D. Etnomatemática e Trandisciplinaridade: A Propósito do Gemaz. In: MENDES, I.A. Educação Matemática e Cultura Amazônica: Fragmentos Possíveis. Belém, PA: Açaí, 2012.

MONTEIRO, A; POMPEU JR, G. A Matemática e os Temas Transversais. São Paulo. Editora Moderna, 2001.

OLIVEIRA, I.L et al. Olhar dos Bolsistas do PET Sobre a Colonização do Piauí. In: SIQUEIRA, C.M.B. Escavando a História de São Raimundo Nonato-PI. São Raimundo Nonato, PI: UNIVASF,2013.

Painel Centenário, Universidade Federal do Vale do São Francisco - UNIVASF, 2012.

PESOS E MEDIDAS - HISTÓRICO: adaptado de "GETEF - Grupo de Estudos em Tecnologia de Ensino de Física". Disponível em:<http://www.fisica.net/unidades/pesos-emedidas-historico.pdf> Acesso em jan.2016.

SCHENEKEMBERG, S.D.S. Questões de Medidas Agrárias na Tribo “Terra Indígena Ivaí”. Londrina, PR: PARANÁ GOVERNO DO ESTADO, 2013. 